\title{
Antibiotic prophylaxis in cardiothoracic surgery in the United Kingdom: current practice
}

\author{
APR WILSON, T TREASURE, MF STURRIDGE, RN GRÜNEBERG \\ From the Department of Cardiothoracic Surgery, Middlesex Hospital, and the Department of Clinical \\ Microbiology, University College Hospital, London
}

ABSTRACT A survey was conducted of the current practice of antibiotic prophylaxis in cardiac
surgery throughout the United Kingdom. Most surgeons $(84 \%)$ use a regimen covering a broad
spectrum of bacterial species that is continued for two to three days after the operation. The most
used regimens are a combination of $\beta$ lactamase resistant penicillin with an aminoglycoside $(44 \%)$
or a single broad spectrum cephalosporin $(30 \%)$. Just $16 \%$ of surgeons preferred a narrow spectrum
regimen effective against only the Gram positive organisms commonly responsible for postoperative
infection in these patients. Antibiotic prophylaxis has been adopted by all cardiac surgeons in the
United Kingdom but is sometimes continued longer than is indicated by the clinical or experimental
evidence.

Prosthetic valve endocarditis following cardiac surgery is an uncommon but disastrous complication with a high mortality rate. It occurs in $0.8 \%$ of patients within two months of surgery. ${ }^{1}$ Sternal wound sepsis is troublesome and a cause of appreciable morbidity in as many as $6 \%$ of patients. ${ }^{2}{ }^{3}$ Thus the use of antibiotic prophylaxis is standard practice. Postoperative infection is usually caused by Gram positive bacteria but, with the emergence of methicillin resistant staphylococci and Gram negative wound and pulmonary infections, there has been increasing use of broad spectrum antibiotic cover. ${ }^{34}$ Opinions on the duration of antibiotic cover vary but evidence is accumulating that a course of two days is as effective as one lasting six days. ${ }^{5}$

We are conducting a prospective randomised trial that compares broad spectrum antibiotic prophylaxis (with flucloxacillin and tobramycin) with the narrow spectrum cover of a new glycopeptide antibiotic, teicoplanin. To find out how our regimens compared with current practice in Britain as a whole, we undertook a postal survey during November 1984-January 1985.

\section{Method}

A list of cardiothoracic surgeons was compiled as comprehensively as possible from a register supplied

Address for reprint requests: Dr APR Wilson, Department of Clinical Microbiology, University College Hospital, London WC1E 6AU.

Accepted 22 November 1985. by the Society of Thoracic and Cardiovascular Surgeons and supplemented by personal knowledge. A questionnaire was sent to the 99 surgeons practising cardiac surgery in the United Kingdom, requesting details of their usual antibiotic regimen, the doses, and the length of the course. Information on the timing of the first dose and the intraoperative use of antibiotics was also sought. Specific antibiotics were listed in the questionnaire for ease of completion and impartiality. Further copies of the same questionnaire were kindly distributed by the Society two months later. Seventy four replies were received and the remaining units were contacted by telephone, so that the usual practice of all surgeons was ascertained.

\section{Results}

Three surgeons working in more than one hospital used different antibiotic regimens in each. Some surgeons used various combinations for different patients and could not easily indicate the most common regimen on the questionnaire. Such difficulties were clarified by telephone.

Only 16 surgeons used narrow spectrum prophylaxis with flucloxacillin or cloxacillin and half of these used a combination with fusidic acid, erythromycin, or benzyl penicillin (figure). The greatest number (44) used fiucloxacillin or cloxacillin with an aminoglycoside to provide broad spectrum cover. Combinations including gentamicin were the most common being used-by 29 surgeons in all. Eight of these surgeons gave benzylpenicillin as well, two used gen- 


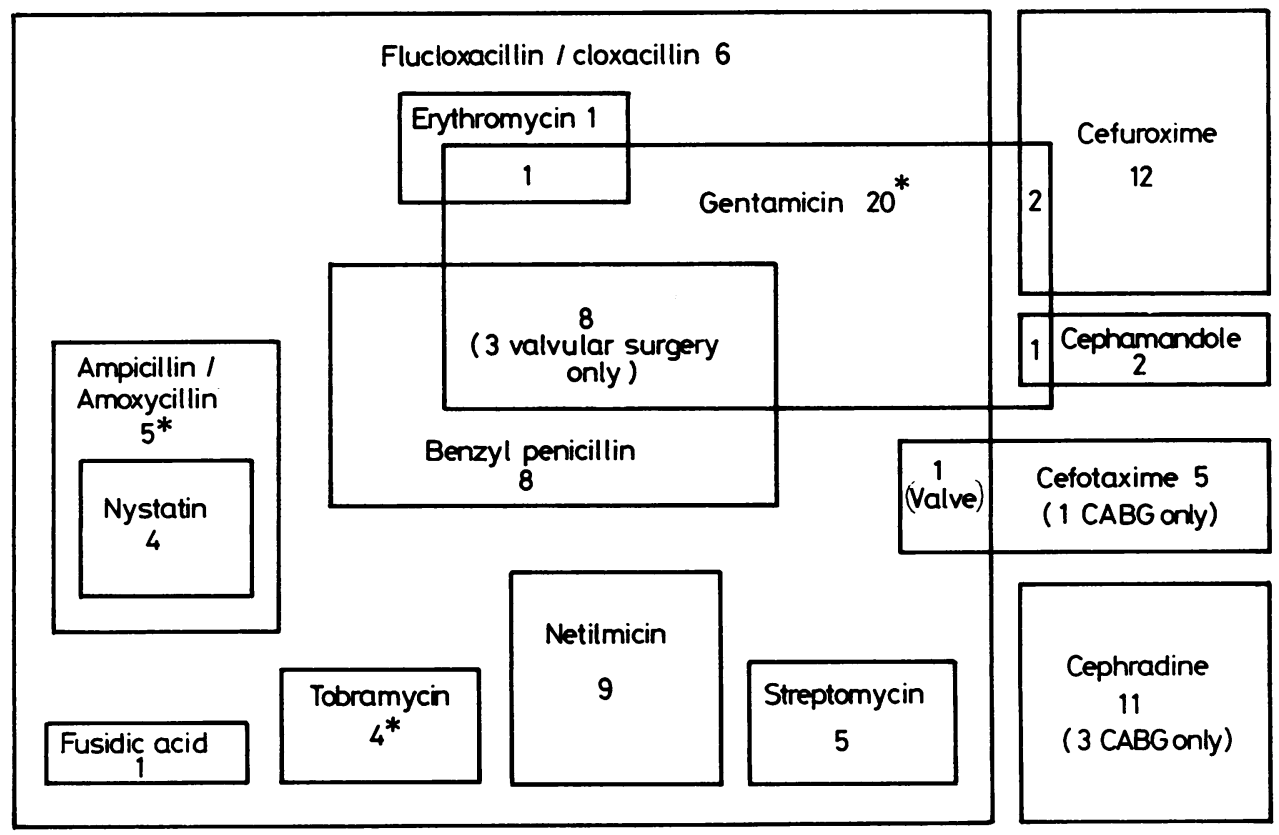

Antibiotic prophylaxis used by 99 surgeons, January 1985. The number of surgeons using each combination is given in the appropriate square; overlapping squares indicate the use of two or more antibiotics. Three surgeons working in different hospitals used different regimens in each.

one hospital but tobramycin in another, and one used ampicillin instead of gentamicin at his second hospital. A further nine used flucloxacillin or cloxacillin with ampicillin/amoxycillin. Four surgeons also gave

Adult dosages in antibiotic prophylaxis

\begin{tabular}{llll}
\hline Antibiotic & Dose $(\mathrm{mg})$ & & $\begin{array}{l}\text { No of } \\
\text { surgeons }\end{array}$ \\
\cline { 2 - 3 } & Range & Mode &
\end{tabular}

\begin{tabular}{|c|c|c|c|}
\hline \multirow{2}{*}{$\begin{array}{l}\text { Penicillins } \\
\text { Flucloxacillin/ } \\
\text { cloxacillin } \\
\text { Benzyl } \\
\text { penicillin } \\
\text { Ampicillin } \\
\text { Amoxycillin }\end{array}$} & $250-1000 / 6 \mathrm{~h}$ & $500 / 6 \mathrm{~h}$ & $73^{*}$ \\
\hline & $\begin{array}{l}500 / 8 \mathrm{~h}-1200 / 6 \mathrm{~h} \\
250-500 / 6 \mathrm{~h} \\
-\end{array}$ & $\begin{array}{l}600 / 6 \mathrm{~h} \\
500 / 6 \mathrm{~h} \\
500 / 8 \mathrm{~h}\end{array}$ & $\begin{array}{l}16 \\
9 * \\
1\end{array}$ \\
\hline $\begin{array}{l}\text { Aminoglycosides } \\
\text { Gentamicin } \\
\text { Tobramycin } \\
\text { Netilmicin } \\
\text { Streptomycin }\end{array}$ & $\begin{array}{l}80 / 8-12 \mathrm{~h} \\
80 / 8-12 \mathrm{~h} \\
200 / 12 \mathrm{~h} \\
500 / 8-12 \mathrm{~h}\end{array}$ & $\begin{array}{l}80 / 8 \mathrm{~h} \\
80 / 8 \mathrm{~h} \\
200 / 12 \mathrm{~h} \\
500 / 12 \mathrm{~h}\end{array}$ & $\begin{array}{c}32^{*} \\
4^{*} \\
9 \\
5\end{array}$ \\
\hline $\begin{array}{l}\text { Cefuroxime } \\
\text { Cephradine } \\
\text { Cefotaxime } \\
\text { Cephamandole }\end{array}$ & $\begin{array}{l}750 / 8 \mathrm{~h}-1000 / 6 \mathrm{~h} \\
500 / 6 \mathrm{~h}-1000 / 6 \mathrm{~h} \\
1000 / 8-12 \mathrm{~h} \\
500-1000 / 6 \mathrm{~h}\end{array}$ & $\begin{array}{l}750 / 8 \mathrm{~h} \\
500 / 6 \mathrm{~h} \\
1000 / 12 \mathrm{~h} \\
500 / 6 \mathrm{~h}\end{array}$ & $\begin{array}{r}14 \\
11 \\
5 \\
3\end{array}$ \\
\hline Erythromycin & $500 / 6 h-600 / 8 h$ & - & 2 \\
\hline
\end{tabular}

*Three surgeons working in different hospitals used different regimens in each. Four surgeons used different regimens for valvular and coronary artery surgery. antifungal cover in the form of oral nystatin.

Cephalosporins were the choice of 33 surgeons but there was no general agreement about which agent should be used. Cefuroxime was the most popular (used by 14 surgeons), the remainder giving cephradine, cefotaxime, or cephamandole. Four surgeons used cephalosporins alone for coronary artery bypass surgery but preferred regimens including flucloxacillin for valvular surgery. For patients having heart transplants aminoglycosides were either omitted from the regimen or replaced by cefotaxime.

Dosages were quite variable but generally corresponded with those used to treat serious established Gram positive sepsis (table). The dose of aminoglycoside was governed by renal function and results of assays. In regimens lasting more than three days intravenous lines were removed and further doses given orally. The first dose of antibiotic was given with premedication by 46 surgeons and with induction of anaesthesia by another 46 . Two surgeons started antibiotics four hours before premedication, one at the time of skin incision, and seven after operation when the patient returned to the intensive care unit. Fifteen surgeons injected antibiotics into the cardiopulmonary pump during operation while 60 did not. The remainder did not indicate their usual practice.

Most surgeons (75) continued antibiotic administration for two to three days, at the end of which the 
intravenous lines were removed. Twelve surgeons, however, gave all their patients a further two days' oral antibiotics and one surgeon continued until the seventh postoperative day. Four surgeons gave extended courses only to patients undergoing valvular surgery. Only six surgeons used antibiotics for 24 hours or less.

For patients with a history of penicillin allergy the most popular alternative was erythromycin, usually combined with an aminoglycoside (36 surgeons). Other surgeons used a cephalosporin (cefuroxime, cefotaxime, cephazolin, cephamandole, cephaloridine, or ceftazidime), with or without an aminoglycoside. Other choices were clinidamycin, fusidic acid, and vancomycin. A secondary regimen was not stated by most units where cephalosporins were the first choice.

\section{Discussion}

Burke reviewed the experimental evidence for the use of preventive antibiotics in surgery. ${ }^{6}$ An antibiotic was most effective in preventing or reducing the size of an artificially induced lesion in guinea pigs, if given in the four hours preceding contamination. There was no advantage in giving an antibiotic for more than four hours after the introduction of bacteria.

The introduction of antibiotic prophylaxis in cardiac surgery 20 years ago was associated with a fall in the incidence of surgical endocarditis. ${ }^{7}$ There were, however, improvements in surgical technique and equipment at the same time. Only one prospective double blind randomised trial has been attempted to compare antibiotics with placebo in valvular surgery. ${ }^{8}$ This was abandoned after two patients in the placebo group developed pneumococcal endocarditis. In the small number studied, antibiotics did not affect the incidence of postoperative infection but altered the range of infecting organisms. In a recent review of papers published from 1973 to 1980, 64 patients died out of 83 who developed prosthetic valve endocarditis within two months of operation, a mortality rate of $77 \% .^{1}$ Our survey indicates the universal use of prophylaxis in valvular surgery in the United Kingdom.

In coronary artery bypass surgery the risk of endocarditis is slight and clinical studies have reached differing conclusions about the value of prophylaxis. One double blind, placebo controlled trial found an extremely high incidence of sternal wound infection in the placebo group ( 10 of 47 patients) by comparison with a group receiving methicillin (none of 57 patients). ${ }^{9}$ A more recent study, comparing cephradine with placebo, had to be stopped when 12 of 22 patients in the placebo group developed sternal wound infection as opposed to only one of the 16 patients treated with cephradine $(p=0.002) .{ }^{10}$ One $\stackrel{0}{x}$ prospective randomised trial of 904 patients has, however, achieved a low rate of sternal wound infection in $\stackrel{5}{+}$ the placebo group $(1.76 \%)$ and failed to show any? significant improvement with the use of antibiotics $\frac{\bar{N}}{\bar{N}}$ $(1.10 \%) .{ }^{11}$ This may reflect differences in operating $\frac{\bar{\sigma}}{\sigma}$ conditions and techniques. Our survey shows that, in $\propto$

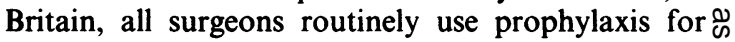
coronary artery surgery.

Most surgeons give antibiotics before skin incision, $\stackrel{\circ}{-}$ ensuring that maximum serum bactericidal activity is $\vec{\omega}$ present at the time of possible contamination; and $\stackrel{\Omega}{\circ}$ some supplement this with further doses during oper- $\overrightarrow{\vec{x}}$

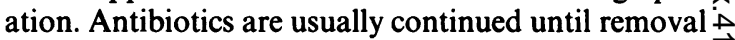
of the central venous lines in the hope that bacterial $\overrightarrow{i r}$ colonisation of the tip of the catheter will be prevented. ${ }^{12}$ Experimental and clinical evidence suggests $\sigma$ that regimens lasting two days or even a single dose do응 not result in a higher incidence of infection than longer courses and they minimise the risk that
resistant strains will emerge. ${ }^{513}$

The organisms most frequently responsible for $\vec{\varphi}$ prosthetic valve endocarditis and sternal wound infection are Staphylococcus aureus and Sepidermidis. ${ }^{12}$. The pathogenicity of coagulase negative staphylococci is being recognised increasingly ${ }^{14}$ and they often possess multiple antibiotic resistance. Most $(63 \%)$ of the Sepidermidis isolates from infected pros- $\stackrel{\circ}{\mathbb{Q}}$

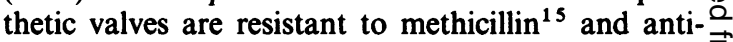
microbial prophylaxis itself promotes the acquisition of resistant strains. Archer and Tenebaum in 1980 found that before operation only $4 \%$ of patients hadF methicillin resistant $S$ epidermidis on the skin of the chest but after a 2-3 day course of antibiotics the proportion rose to $53 \% .{ }^{16}$ Although $80 \%$ of these strains were also resistant to cephamandole, gen- $-x$ tamicin resistance was present in only $20 \%$. Gram 3 . negative organisms may also cause sternal wound infections after coronary artery bypass surgery, possi-을 bly as a result of their transfer from the leg at the time of vein removal. ${ }^{4}$ Thus a combination of flucloxacillin? with an aminoglycoside improves cover against $\frac{D}{0}$ methicillin resistant and Gram negative organisms. Nevertheless, a prolonged course would still encour-N age the growth of an even more resistant flora. N

The cephalosporins have a broad spectrum of activity and low toxicity and some, such as cefuroxime and $\omega$ cephamandole, show favourable pharmacokinetic behaviour during cardiopulmonary bypass. ${ }^{1718}$ Their을 activity against methicillin resistant staphylococci may, however, be unreliable and is more difficult to ${ }_{-}^{+}$ test in the laboratory. ${ }^{19}$ This may explain why they are less popular in Britain than in the United States, $\underset{\mathbb{D}}{\mathbb{P}}$ where the many published trials and one survey of $\frac{\vec{Q}}{\mathbb{Q}}$ paediatric practice ${ }^{20}$ suggest that their use is wide- $\varrho$ spread. 
Unfortunately, in practice the relative effectiveness of narrow versus broad spectrum antibiotic prophylaxis is difficult to ascertain. In the published clinical trials there is no widely accepted definition of an "infected" wound and infection rates vary between different surgeons and hospitals irrespective of the regimen used. Furthermore, the overall incidence of wound sepsis and prosthetic valve endocarditis is low and significant differences between regimens can be detected only by using large numbers of patients. We do not know of any prospective controlled trial comparing the use of flucloxacillin alone with a combination of flucloxacillin and gentamicin. The increasing use of netilmicin is probably related to its superior tissue penetration and its activity against some gentamicin resistant staphylococci but any practical advantages have yet to be demonstrated. ${ }^{2122}$

Several clinical trials have compared cloxacillin or methicillin with cephalosporins. One trial of 217 patients showed methicillin, cephalothin, and cephapirin to be equally effective as prophylactic agents. ${ }^{23}$ Another series, however, noted three cases of surgical endocarditis in 129 patients given methicillin, of which two were caused by staphylococci and one by Serratia marcescens. There were no cases of endocarditis in a similar group given cephalothin. The incidence of Gram negative urinary tract infection and pneumonia was significantly greater in those patients given methicillin but there was no difference in the occurrence of wound infections. ${ }^{3}$ Unfortunately, the total daily doses of cephalothin $(4 \mathrm{~g})$ and methicillin $(2 \mathrm{~g})$ were not comparable. In another study fewer pathogens were isolated from the respiratory tracts of patients given cephamandole than from those of patients given penicillin and flucloxacillin but this study failed to show any difference in the incidence of wound infection. ${ }^{24}$ Two other trials comparing cefazolin with penicillin flucloxacillin and streptomycin and cephalothin with cloxacillin and gentamicin showed no difference in infectious complications in small numbers of patients. ${ }^{25} 26$ Finally, cephamandole has been compared with a combination of ampicillin and cloxacillin in 109 patients. ${ }^{27}$ Only four cases of severe sternal wound sepsis occurred, one in the cephalosporin group and three in the ampicillin and cloxacillin group; all were due to Saureus. Two of the patients in the latter group subsequently developed prosthetic valve endocarditis.

Despite the theoretical considerations therefore clinical trials generally fail to show any significant difference in the incidence of surgical endocarditis or wound infection between narrow and broad spectrum prophylaxis. The regimens with a broader spectrum cover, however, probably reduce the frequency of postoperative respiratory and urinary infections. Nevertheless, these would be better treated specifically in case a more resistant microbiological flora is promoted.

We thank all the members of the Society of Thoracic and Cardiovascular Surgeons for cooperating with this survey. One of us (APRW) is a research registrar funded by a grant from Merrell Dow Pharmaceuticals Ltd.

\section{References}

1 Wilson WR, Danielson GK, Giuliani ER, Geraci JE. Prosthetic valve endocarditis. Mayo Clin Proc 1982; 57:155-61.

2 Bor DH, Rose RM, Modlin JF, Weintraub R, Friedland GH. Mediastinitis after cardiovascular surgery. Rev Infect Dis 1983;5:885-97.

3 Myerowitz PD, Caswell K, Lindsay WG, Nicoloff DM. Antibiotic prophylaxis for open heart surgery. $J$ Thorac Cardiovasc Surg 1977;73:625-9.

4 Wells FC, Newsom SWB, Rowlands C. Wound infection in cardiothoracic surgery. Lancet 1983;i:1209-10.

5 Goldmann DA, Hopkins CC, Karchmer AW, et al. Cephalothin prophylaxis in cardiac valve surgery. A prospective double blind comparison of 2 day and 6 day regimes. J Thorac Cardiovasc Surg 1977;73:470-9.

6 Burke JF. Preventative antibiotic management in surgery. Annu Rev Med 1973;24:289-94.

7 Firor WB. Infection following open heart surgery with special reference to the role of prophylactic antibiotics. J Thorac Cardiovasc Surg 1967;53:371-8.

8 Goodman JS, Schaffner W, Collins HA, Battersby EJ, Koenig MG. Infection after cardiovascular surgery, clinical study including examination of antimicrobial prophylaxis. $N$ Engl J Med 1968;278:117-23.

9 Fong IW, Baker CB, McKee DC. The value of prophylactic antibiotics in aorta coronary bypass operations. A double blind randomised trial. $J$ Thorac Cardiovasc Surg 1979;78:908-13.

10 Penketh ARL, Wansbrough-Jones MH, Wright E, Imrie F, Pepper JR, Parker DJ. Antibiotic prophylaxis for coronary artery bypass graft surgery. Lancet 1985;i:1500.

11 Sutherland RD, Martinez HE, Guynes WA, La Wayne Miller BA. Postoperative chest wound infections in patients requiring coronary bypass. $J$ Thorac Cardiovasc Surg 1977;73:944-7.

12 Freeman R, King R. Analysis of results of catheter tip cultures in open heart surgery patients. Thorax 1975; 30:26-30.

13 Conte JE, Cohen SN, Roe BB, Elashoff RM. Antibiotic prophylaxis and cardiac surgery, a prospective double blind comparison of single dose versus multiple dose regimens. Ann Intern Med 1972;76:943-9.

14 Sewell CM, Clarridge JE, Young EJ, Guthrie PK. Clinical significance of coagulase negative staphylococci. J Clin Microbiol 1982;39:236-9.

15 Archer GL. Antimicrobial susceptibility and selection of resistance among Staphylococcus epidermidis isolates recovered from patients with infections of indwelling foreign devices. Antimicrob Agents Chemother 1978; 14:353-9.

16 Archer GL, Tenenbaum MJ. Antibiotic resistant Staphylococcus epidermidis in patients undergoing cardiac 
surgery. Antimicrob Agents Chemother 1980;17:269-72.

17 McGregor C, McLeod M, Smith J, Cameron E, Eilon L. Cefuroxime concentrations during open heart surgery. In: Cefuroxime Update: London: Academic Press and Royal Society of Medicine, 1981:63-8. (Royal Society of Medicine International Congress and Symposium Series No 38.)

18 Polk RE, Archer GL, Lower R. Cephamandole kinetics during cardiopulmonary bypass. Clin Pharmacol Ther 1978;23:473-80.

19 Blowers R, Stokes EJ, Abbott JD. Antibiotic sensitivity tests [Letter]. Br Med J 1973;iii:46-7.

20 Faden H. Prophylactic antibiotics in paediatric cardiovascular surgery: current practices. Ann Thorac Surg 1981;31:211-3.

21 Stanbridge TN, Greenall DJB. Netilmicin prophylaxis in open heart surgery. J Antimicrob Chemother 1984;13, suppl A:59-66.

22 Phillips I, Smith A, Shannon K. Antibacterial activity of netilmicin, a new aminoglycoside antibiotic, compared with that of gentamicin. Antimicrob Agents Chemother. 1977;11:402-6.

23 Effler DB, Gensini GG, Giambartomei AA. A comparative study of cephapirin, cephalothin and methicillin in cardiovascular surgery. Surgery 1976;79:89-96.

24 Bailey JS, Percival HG. Cefamandole as a prophylactic antibiotic in cardiac surgery. Scand J Infect Dis 1980; suppl 25:112-7.

25 Cooper DKC, Norton R, Mobin MA, Cleland WP, Bentall HH, Darrell JH. A comparison of two prophylactic $\vec{\circ}$ regimes for open heart surgery. $J$ Cardiovasc Surg 1980;21:279-86.

26 Hill. DG, Yates AK. Prophylactic antibiotics in open heart surgery. $N Z$ Med J 1975;81:414-7.

27 Ghoneim AT, Tandon AP, Ionescu M. Comparative study of cefamandole versus ampicillin plus cloxacillin: $₫$ prophylactic antibiotics in cardiac surgery. Ann Thorac ir Surg 1982;33:152-8. 